\title{
EL MUNICIPIO EN EL PERÚ
}

El presente artículo relata bajo una reseña histórica la creación, solidificación y reconocimien to del municipio en el Perú a lo largo de los años, también, narra la problemática y la necesidad de éstos desde el periodo incaico hasta la actualidad. Este también menciona las leyes y los artículos que lo compusieron e intervinieron en su formación. Luego éste nos menciona lo importante que eran y que son debido a que es una forma de organización de la sociedad y es un sistema usado en todo el mundo. Finalmente, nos da el significado de municipio, de donde deriva esta palabra, y nos brinda una visión de municipio en la antigua Roma.

\section{Summary}

The present article relates below a historie review the creation, solidificadon and recognition of municipality in Perú along the years until present, also, nárrales the problematic and necessity of these from Inca period until now. This article also mentions the laws and árdeles that composed it and were involved in its formadon. Then these mentions us the importance of them in past and preseni because is a way of societv s organizadon and is a syslem used around the world. Finally, the árdele gives us the meaning of municipality ${ }^{1}$, from where drifts this word and provides us a visión of municipality in the antigüe Rome.

\section{Sommaire}

Le présent árdele raconte, sous un angle historique la création, consolidadon et reconnaissance de la municipalité au Pérou á travers le temps. II décrit également la problémadque et la nécessite de ces derniéres depuis la période inca jusqu 'á l'actualité. En outre, /'árdele mendonne les lois et árdeles qui la composent et sont á I'origine de sa formadon. Ensuite, I 'articule nous mendonne son importance étant donnée que la municipalité consdtue une forme d'organisadon sociale et un systéme utilisépartout dans le monde. Finalement, l'árdele nous donne la significadon de municipalité ainsi que $l$ 'origine $d u$ mol et nous propose, pour terminen une visión de la municipalité dans la Rome andque. 


\section{INTRODUCCIÓN}

Nuestro país, se constituye en un estado soberano y democrático en donde la democracia es ejercida por cada uno de sus ciudadanos libres con derecho y obligaciones, siendo el primer extremo de manifestación democrática, la libertad de expresión y el segundo es el derecho y obligación que como ciudadanos teneos para acercarnos a nuestro estado, este aspecto resulta importante por cuanto un municipio se constituye en el espacio tísico de la jurisdicción en la que vivimos en la cual debemos elegir entre nuestros vecinos a quienes consideramos los más adecuados para lograr el desarrollo de nuestro distrito y nuestra provincia.

El municipio es sin duda el acercamiento más próximo que tenemos como ciudadanos al Estado, nuestro municipio es un pequeño gobierno en donde pagamos tributos y los mismos deben ser revertidos en beneficios de diversos servicios públicos que deben brindarnos.

Existe diferencia entre lo que es el significado de municipio. Gobierno Municipal y Municipalidad, el primero de ellos se constituye en el espacio físico que ha sido demarcada por ley (Jurisdicción), siendo la segunda acepción la Gestión Municipal que está ejerciendo el gobierno en un determinado tiempo, cuyas autoridades máximas (alcaldes y regidores) han sido elegidos por elección directa de la ciudadanía ejerciendo el voto popular y el término Municipalidad, es el predio público al cual los ciudadanos podemos acudir para ejercer nuestros derechos como ciudadanos y como vecinos.

Bajo este contexto es importante efectuar una breve descripción del desarrollo de los Municipios en el Perú, remontándonos para ello al Periodo Incaico, al Colonial y al Republicano.

\section{I. PERIODO INCAICO}

El municipio en el Perú se origina en las comunidades agrarias Ayllus, en virtud de dichas formas de organización comenzó a esbozarse la organización estatal. El sistema de organización entre otros, se basaba en agrupaciones de familias las cuales podían ser de 500 y hasta 1000 familias y así sucesivamente, las cuales, se encontraban a cargo de jefes o cabezas de familias. Dichas agrupaciones se dedicaron 
a la labranza, pastoreo y artesanía entre otras actividades que realizaban para atender a sus necesidades.

El Estado Inca se basó en la relación que existía entre los jefes locales y el monarca. Los diversos pueblos se encontraban diseminados en el territorio y tuvieron que vivir aferrados al localismo. Al crearse los caminos y gracias a la estadística se permitió un mayor control por parte del poder central. De este modo el Estado de los Incas se hasó de un lado en el campesino como fundamento de la vida económica y del otro, en el funcionario y el guerrero como fundamento de la vida política.

Los incas concibieron al Estado en su sentido de órgano divisor del trabajo, frente al cual tiene el individuo deberes ineludibles y exactos pero del cual a su vez recibe beneficios y privilegios. 


\section{PERIODO COLONIAL}

Durante la colonia, el municipio establece y desarrolla teniendo como base el modelo Español. Las autoridades eran designadas por el Virrey y en algunos casos por el propio Rey de España.

En el Perú, el conquistador Francisco Pizarro, de conformidad con las prerrogativas que le fueron concebidas por la Real Cédula suscrita en Toledo el 4 de Mayo de 1534, al fundar la ciudad de Lima, designó su primer cabildo el 22 de Enero de 1535, nombrando alcaldes y regidores, instalado el primer cabildo de Lima comenzó su vida institucional caracterizada por ser democrática y provista de poder suficiente para que dentro de su jurisdicción ejerciese autoridad.

Establecida la colonia española, primero y fugazmente aparece como gobernación (Nueva Castilla y Nueva Toledo) a consecuencia de la capitulación de Toledo el 26 de Junio de 1529. El virreinato -forma más elevada del dominio Españoles la de más larga duración: 282 años. Desaparecidos Diego de Almagro y Francisco Pizarro, las gobernaciones referidas dejan de existir. Surgen en 1569 los corregimientos y los partidos como sub-unidades político administrativas, pero lateralmente hay una organización económico-social-religiosa, que son los repartimientos y encomiendas, sea la población de un determinado valle o lugar encomendada a los llamados conquistadores para su adoctrinamiento católico y su inhumana explotación en la vida real. Otra organización eran los obispados, bajo el control del arzobispo de Lima. De este modo se establecen las intendencias y las subdelegaciones, en reemplazo de los 47 corregimientos; se trata de un novedoso régimen divisional, aún así es el más cercano a la técnica moderna. El abastecimiento de la ciudad era responsabilidad del funcionario denominado fiel ejecutor que se ocupaba de la provisión de los artículos alimenticios, control de la higiene de los mismos, de pesa y medidas y de todo lo concerniente a la recaudación de las rentas municipales.

Por otro lado, los cargos concejales fueron en un comienzo, gratuitos, obligatorios y electivos, siendo órganos representativos de la ciudad y determinando una forma espontánea del gobierno representativo. Es a partir de 1594 en que comienza su decadencia, al comprarse y venderse los puestos comunales y al intervenir virreyes y gobernantes, transformándose en organismos burocráticos. No obstante lo ocurrido, la personalidad de la institución subsiste y en las postrimerías de la colonia recobra su importancia, convirtiéndose el apoyo del gobierno representativo. En esta situación la independencia es proclamada en vibrantes reuniones de Cabildo abierto, por el concurso del pueblo, y los cabildos asumen autoridad pública al producirse la acefalía del gobierno local.

\section{PERIODO REPUBLICANO}

\subsection{El estatuto provisional de 1821}

Dictada el 8 de octubre de 1821 por el General San Martín, cuya sección sexta contiene los artículos a las municipalidades donde decía: "las municipalidades subsistirán de la misma forma que hasta aquí y serán presididas por el presidente del Departamento". Además se establecía que la elección de sus miembros se haría por 
sufragio popular. En todo pueblo cualquiera que fuera el número de sus habitantes debía haber un municipio. Entre sus atribuciones se consideraba la instrucción pública y la salubridad. Los alcaldes eran jueces de Paz. Nadie podía excusar de servir los cargos concejales.

\section{2. $\quad$ Constitución de 1823}

La Constitución de 1823 establecía en su artículo $138^{\circ}$ que "en todas las poblaciones sea cual fuere su censo, habrá municipalidades". No requería población determinada ni patrimonio económico; las necesidades de una población justifican la necesidad de un Gobierno Municipal. Entre sus atribuciones podemos destacar, velar por la instrucción primaria, por la salud pública, por el orden y la seguridad, por el ornato y comodidad del vecindario. Los concejos municipales tenían funciones precisas en beneficio de la comunidad, sus omisiones o descuidos debían ser justificados o explicados. Las adhesiones e incondicionalidades no daban derecho a ser miembro de un concejo; la incapacidad y la negligencia no eran toleradas. Honestidad y eficiencia eran cualidades necesarias para formar parte de los organismos de gobierno local. Los alcaldes ejercían además en sus respectivas localidades, las funciones de juez de paz; y en las poblaciones más numerosas, ejercían esas funciones los regidores.

Con el objeto de garantizar el carácter electivo de los funcionarios municipales, Bolívar promulga la ley reglamentaria del 3 de marzo de 1825, la cual, es una verdadera ley de elecciones, en ella se determina las condiciones que debe reunirse para ser elegido o para ser lector municipal. Era menester ser ciudadano en ejercicio, vecino y residente en la parroquia, tener propiedad que produzca trescientos pesos, cuando menos al año, o ejercer cualquier arte, oficio, estar ocupado en alguna industria útil o ser profesor público de alguna ciencia. La Constitución y la ley reglamentaria contenían disposiciones acertadas tanto en lo que se refiere a la necesidad de crear órganos de Gobierno Local para todo centro poblado, cuanto en la necesidad de defenderlo de toda intromisión extraña, el Gobierno Local era de incumbencia de los vecinos, ellos y sólo ellos, tenían derecho a intervenir en el gobierno y administración municipal, la intromisión de personas extrañas, incluyendo las autoridades superiores, estaban prohibidas por las leyes superiores.

\subsection{Constitución de 1828}

Derogada la constitución vitalicia de 1826 por el Congreso general constituyente de 1827, se expidió la Constitución de 1828, los legisladores de aquella época hicieron depender del factor población la existencia de los municipios. Con ese criterio en el artículo $140^{\circ}$ de dicha constitución se establecía que en toda población que por el censo deba tener Colegio Parroquial habrá una junta de vecinos denominada municipalidad. Además, se establecía que las municipalidades tienen la dirección de sus intereses locales y que las disposiciones que se tomen sobre ellas están sujetas a la aprobación de las juntas departamentales y que no pueden ser contrarias a las leyes ni al interés general y que sus peticiones a las autoridades deben ceñirse exclusivamente a las necesidades domésticas de los pueblos. 


\section{4. $\quad$ Constitución de 1834}

Esta constitución no tenía en cuenta el factor población ni las necesidades sociales para crear o reconocer los municipios. En su artículo $137^{\circ}$ establecía que "en las capitales de departamentos y provincias, habrá una junta de vecinos denominada Municipalidad"; los distritos y centros poblados no necesitaban de dicha junta, según los constituyentes de 1834. Se dispuso además, que la formación de esas municipalidades, localidad de sus componentes, sus atribuciones y obligaciones, tiempo de duración y demás procedimientos, estarían regulados por una Ley Orgánica de Municipalidades. $Y$ es en cumplimiento de esa disposición constitucional que se dicta la primera Ley Orgánica de Municipalidades el $I^{\circ}$ de agosto de 1834 y la ley de elecciones municipales, el 29 del mismo mes y año.

Según la Ley Orgánica de Municipalidades en las ciudades y lugares más poblados, funcionarían jueces de paz y notables. Además señala la referida Ley Orgánica los requisitos para ser miembro de los Consejos Municipales, establece las atribuciones de esos órganos de gobierno y de sus miembros, señala el periodo de sus funciones y enumera los servicios comunales que deben ser atendidos. Dispone también que las elecciones municipales se realicen con arreglo a la Ley de Elecciones Municipales.

Empero, esa ley electoral era francamente reaccionaria. Concedía el derecho de elegir y ser elegidos a los propietarios y ciudadanos que disponían de rentas y tenían que trabajar para vivir, los mendigos carecían de este derecho fundamental por expresa disposición del Artículo $6^{\circ}$, inc. 3 . Según la constitución debían ser gobernadas por concejos municipales sólo las capitales de departamentos y de provincias. Las otras poblaciones, distritos, villas y aldeas, por más pobladas que fueran carecían de función municipal, no tenían derecho a municipalidades, eran gobernadas por Jueces de Paz y Notables, nombrados por la autoridad central, teniendo en cuenta su incondicionalidad y no su honestidad ni competencia.

Según la Ley de Elecciones Municipales el Derecho de Sufragio estaba reservado sólo a los propietarios y a los que disponían de rentas; no era un derecho universal sino privilegiado. Para los hombres de 1834 el Gobierno Municipal no era función vecinal, correspondiente a todos los centros poblados como un derecho natural sino función política, como creación de la ley, reservada a capitales de departamento y provincia.

El Presidente provisorio de ese entonces General Don Luis José Orbegoso, elegido por la Convención Nacional encargada de reformar la Constitución de 1828 al haber concluido el mandato del Mariscal Gamarra; suprimió la realización de elecciones y por un decreto le entregó el gobierno Municipal de Lima, a un intendente de policía, el cual ejercería las atribuciones municipales hasta la conclusión de las guerras que en ese entonces afectaba a nuestro país. Posteriormente y por no haberse verificado la elección de los individuos que deben componer las Municipalidades, debido a los trastornos políticos de la República, amplió el decreto anterior recesando todas las municipalidades y junta de notables de la República hasta la conclusión de la guerra.

En dicho decreto se disponía que se nombre en cada Capital de Departamento un intendente de policía, con el ejercicio de todas las atribuciones de la municipalidad y en las provincias las desempeñarían los subprefectos. A esos funcionarios policiales, se les entregó el Gobierno Local, el manejo de los fondos municipales, sin presupues- 
to y sin control, no se aceptaron nada de autonomías, la autoridad de los que detentaban el poder debía imperar debían de cumplirse sin observación y sin crítica.

La Constitución de Huancayo de 1839 otorgada por Agustín Gamarra suprimió las Municipalidades y abolió las juntas departamentales, creando las intendencias, a cargo de funcionarios dotados de facultades ejecutivas, sociales y de policía, nombradas por el gobierno.

\section{5. $\quad$ Constitución de 1856}

Luego de haberse restablecido las Municipalidades por ley de 9 de diciembre de 1853 , y no obstante haberse dedicado título especial a esos organismos de gobierno en la Constitución del 13 de octubre de 1856, estos no funcionaron hasta el primero de diciembre de ese año. La constitución de 1856 dedica el Capítulo XV a la organización y funcionamiento de las municipalidades. En sus artículos $114^{\circ}$ y $115^{\circ}$ establece que habrá Municipalidades organizadas conforme a la ley en todos los lugares que ésta designe. Además correspondía a las Municipalidades la administración, el cuidado y fomento de los intereses locales y de los establecimientos respectivos que se hallaren dentro de su territorio, les correspondía igualmente la formación y conservación del registro cívico y del censo de las poblaciones con arreglo a la ley.

La Ley Orgánica de Municipalidades del 29 de Noviembre de 1856, aclarando la disposición constitucional que citamos, establecía que "habrá Municipalidades en todas las capitales de distrito de la República y en las poblaciones que, aunque no sean capitales de distrito, tengan más de mil habitantes y para la población de menos de mil habitantes se nombrarían Agentes Municipales". El propósito fue que todo pueblo, por escasa población que tuviera, debía tener administración y gobierno municipal. El número de Munícipes o concejales estaba condicionado al número de habitantes. En las capitales de distrito aún cuando no tuvieran mil habitantes, el Concejo se formaría siempre de cinco municipales, y en los demás pueblos de menos mil habitantes funcionaban tres agentes municipales nombrados por la Municipalidad inmediatamente superior. El poder central no intervenía en lo menor.

Los Concejos Municipales según la referida Ley Orgánica, se constituían por sufragio directo de los ciudadanos en ejercicio, domiciliados en el distrito municipal. El artículo $15^{\circ}$ de la comentada Ley, hace una declaración sustancial de contenido autonomista. Cada Municipalidad dice- "tendrá un reglamento formado por ella misma, para facilitar el cumplimiento de las funciones de la corporación (...) según las necesidades y medios del municipio". Un reglamento de las municipalidades de toda la república. El reglamento dictado por la Municipalidad de Lima por ejemplo, no podía funcionar con eficacia en todas las Municipalidades del Perú, sencillamente porque las necesidades de dichas Municipalidades no son ni pueden ser las mismas.

\subsection{Constitución de 1860}

La Constitución de 1860 fue producto de la intolerancia de quienes detentaban el poder, los logros alcanzados por la Constitución de 1856 entre las cuales encontramos la facultad de que se concedía a los concejos municipales para reclamar contra los funcionarios del poder ejecutivo que no cumplieran con la constitución, con la ley electoral o con las relativas a su departamento, esta conquista junto con las demás que 
proclamaban principios que hoy se denominan de Justicia Social, desaparecieron en la Constitución de 1860 , se suprimen las Juntas Departamentales con el pretexto de economía y de falta de eficacia, y por efecto de dichas medida las provincias volvieron al capricho de los gobernantes.

Comprendieron que las provincias con libertad de acción y los concejos municipales con autonomía serían baluartes de democracia y civilidad; y eso no podía permitirse. La Constitución de 1860 dedica a las municipalidades tan sólo un precepto normativo. El artículo $118^{\circ}$ decía: "habrá municipalidades en los lugares que designe la ley, la cual determinará sus funciones, responsabilidad, calidad de sus miembros y el modo de su elección".

Es decir, no debían ser los pueblos titulares de la soberanía, aquellos que debían determinar la existencia de los organismos municipales, sino la ley, la voluntad de los denominadores erigidos en legisladores. Los legisladores de 1960 fueron centralistas en grado sumo. Lo dicho en la constitución fue aplicado por la Ley Orgánica del 9 de mayo de 1861.

\section{7. $\quad$ Constitución de 1867}

En su Artículo $115^{\circ}$, establecía que habrá municipalidades en las capitales de provincia y en las ciudades aun cuando no tengan este carácter; y agencias municipales en los distritos. Dejando a una ley la determinación de sus funciones, responsabilidad. calidades de sus miembros y el modo de elegirlos. Con fecha 14 de octubre de 1892 se dictó la Ley Orgánica de Municipalidades, la que rigió hasta el 17 de marzo de 1981. Según dicha ley "la Administración Municipal de la República se ejerce por los concejos provinciales y de distrito"; los Concejos Provinciales tienen la facultad de inspeccionar los procedimientos de los distritos y de conocer en revisión sus resoluciones. Asimismo, los actos del Concejo Provincial de Lima estaban sujetos a la revisión del gobierno. El personal del Municipio se constituía por elección directa. Reconociendo la diversidad de las necesidades de las provincias, se faculta a los concejos formular sus reglamentos interiores, ciudadano de que no se opongan a las leyes vigentes, señala las atribuciones y funciones de los concejos encomendándoles entre otras cosas la obligación de velar por la higiene y la salubridad de su circunscripción, por la conservación de manantiales, por el fomento de la instrucción primaria y, además, tenían la facultada de controlar y reglamentar los espectáculos públicos. Los legisladores de entonces demostraron tener un concepto claro sobre municipio y Concejo Municipal, sobre autonomía y gobierno local y sobre las atribuciones y deberes de los concejales.

Ley 1072, fue promulgada el 06 de marzo de 1909, la cual reformaba el procedimiento para las elecciones municipales. En esa ley se establecía que las elecciones municipales fueran por voto directo y público, se reconocía derecho a sufragio a los vecinos de las circunscripción, peruanos y extranjeros, mayores de veintiún años o casados, que sepan leer y escribir e inscritos en el registro de electores municipales. La renovación del personal de los concejos municipales se haría totalmente cada dos años. Esta ley encausó las elecciones municipales en la República hasta 1919. 
Ley 4012, del 8 de diciembre de 1919, dispuso la realización de elecciones municipales en toda la República, se disponía que los alcaldes provinciales fueran elegidos directamente por el pueblo, quedando modificado en este punto el artículo $74^{\circ}$ de la Ley de Municipalidades. En dicha ley se autorizaba al ejecutivo nombrar Municipalidades Provisionales que asuman inmediatamente las labores comunales, hasta que se efectúen las elecciones municipales. Pero esas elecciones no se realizaron en todo el oncenio de Leguía, por tal razón las municipalidades provinciales se convirtieron en permanentes.

4.8 .

\section{Constitución de 1920}

En su Título XVI se ocupaba de las municipalidades y en sus artículos $141^{\circ}$ y $142^{\circ}$ establecía que habrá municipalidades en los lugares que designe la ley, la cual determinará sus funciones, responsabilidad, cualidades de sus miembros y el modo de elegirlos; los Concejos Provinciales son autónomos en el manejo de los intereses que les están confiados, la creación de arbitrios será aprobada por el gobierno.

Con esta Ley 7482 dada el 19 de Enero de 1932 se autoriza al poder ejecutivo para que nombre Municipalidades provisionales en las capitales de departamento y de provincias, mientras se verifiquen las elecciones de conformidad con la Ley Orgánica de Municipalidades que habría de ser dictada por los constituyentes del 33.

Constitución de 1979

En su Capítulo XII, artículos del $252^{\circ}$ al $258^{\circ}$ establecían que las Municipalidades son los órganos de Gobiernos Locales y cuentan con autonomía económica y administrativa en los asuntos de su competencia. Asimismo disponía que la administración se ejerce a través de los Concejos Municipales Provinciales, distritales y los que se establezcan conforme a ley. Los Alcaldes y Regidores de los Concejos Municipales son elegidos en sufragio directo, por los vecinos de la respectiva jurisdicción. Los extranjeros residentes por más de dos años continuos pueden elegir, también pueden ser elegidos salvo en las Municipalidades fronterizas. El Concejo Municipal es presidido por el alcalde.

Las Municipalidades son componentes para: acordar su régimen de organización interior, votar su presupuesto, administrar sus bienes y rentas; crear, modificar o suprimir sus contribuciones, arbitrios y derechos; regular el transporte colectivo, la circulación y el tránsito; organizar, reglamentar y administrar los servicios públicos locales; contratar con otras entidades públicas o privadas, preferentemente locales, la atención de los servicios que no administran directamente; planificar el desarrollo de sus circunscripciones y ejecutar los planes correspondientes; y las demás atribuciones inherentes a su función de acuerdo a ley.

Las municipalidades provinciales a su cargo, además de los servicios públicos locales, la zonificación, educación primaria y vigilancia de su normal funcionamiento; cultura, recreación y deporte; turismo y conservación de monumentos arqueológicos e históricos, en coordinación con el órgano regional; cementerios; y los demás servicios cuya ejecución no está reservada a otros organismos públicos que tienden a satisfacer necesidades colectivas de carácter local. 
El Poder Ejecutivo con facultades otorgadas por el Congreso dictó la Ley Orgánica de Municipalidades, previa revisión a cargo de la comisión permanente de Congreso. El Decreto Legislativo 51 promulgado el 16 de marzo de 1981, y posteriormente fue derogado por Ley 23853, promulgada el 08 de junio de 1984.

\subsection{Constitución de 1993}

La presente constitución en comparación con la de 1979 aborda brevemente el tema Municipal, introduciendo la autonomía política a las ya existentes administrativas y económicas. Entre otros puntos, establece un periodo de cinco años para el cargo de alcaldes y regidores. Se regulan además, la competencia de las municipalidades, sobre sus bienes y rentas, la posibilidad de concertar convenios cooperativos con otros municipios y una disposición sobre el régimen especial de determinadas Municipalidades.

La Ley Orgánica de Municipalidades vigente Ley 27972 fue dada bajo el amparo de la Constitución de 1993, y se constituyó en una ley necesaria habida cuenta que había que adecuarla a lo dispuesto en la actual carta magna, por cuanto la anterior ley orgánica fue dada mediante la vigencia de la Constitución de 1979.

Esta Ley Orgánica de Municipalidades, hace que los municipios adopten una estructura gerencial, siendo sus unidades orgánicas administrativas, gerencias y no direcciones como anteriormente se solía denominar, por otro lado, el concejo al contar con funciones legislativas y fiscalizadoras, actúa como un parlamento dando normas en el ámbito de competencia y fiscalizando la labor de los otros organismos. El alcalde es quien hace las veces del ejecutivo, siendo además el personero de la Municipalidad y autoridad que toma las decisiones administrativas.

Otro de los temas que aborda la Constitución de 1993 es sobre la regionalización, el cual se ha convertido en casi un mito para nuestro país. Como se sabe, el debate que precedió a las dos últimas constituciones -con más interés en la Carta de 1979 que en la de 1993- se trató sobre la descentralización.

La regionalización implica un proceso más complejo que la descentralización y desconcentrar. La región es un determinado espacio geográfico de territorio en el cual existen diversos organismos que, si bien quedan sometidos al Gobierno Central en materia de armonización de políticas y normatividad general, adquieren sin embargo, dentro de su región una cuota de poder que antes mantenía el Gobierno Central.

En su Título X crea los Concejos Departamentales, en sus Artículos del $202^{\circ}$ al 206" señalaba que la Ley Orgánica de Concejos Departamentales establecería la existencia su organización, sus atribuciones, su funcionamiento y todo lo que no esté previsto en la constitución. Asimismo, se establecía la existencia de concejos municipales en las capitales de provincia, de distrito y en los pueblos que determine el respectivo Concejo Departamental. Por otro lado los Concejos Municipales provinciales contaban con autonomía administrativa y económica en el ejercicio de las funciones que les correspondían conforme a las leyes.

La Ley 10233 de 04 de setiembre de 1945 reemplazó los Concejos provinciales y distritales por Juntas Municipales Transitorias. La Ley 10733 de 05 de diciembre de 1946, normó el procedimiento para las elecciones de las municipalidades por sufragio directo y secreto, siendo obligatoria para los varones menores de 60 años. La Ley 14669, Ley de Elecciones Municipales de 24 de setiembre de 1963, la cual establecía 
la elección en cada provincia de un Concejo Municipal Provincial y Consejos Distritales en los distritos que no sean capitales de provincia.

El Gobierno Revolucionario de la Fuerza Armada, dictó el 25 de julio de 1978 el Decreto Ley 22250 al que llamó "Ley de Municipalidades".

\section{COMCEPTL1ALIZACIÓN DEL MUNICIPIO}

El municipio es la entidad territorial fundamental de la división político administrativa del Estado, con autonomía política, fiscal y administrativa, dentro de los límites que le señalen la Constitución y la ley y cuya finalidad es el bienestar general y el mejoramiento de la calidad de vida de la población en su respectivo territorio.

El municipio es la base de organización y está compuesto por el territorio, la población que vive en ese territorio (hayan nacido ahí o en cualquier otro lugar), y el gobierno. La forma, los límites, los derechos y obligaciones de cada una de estas partes están definidas en las leyes: la Constitución Política del Estado y sobre todo en la Ley Orgánica Municipal además de otras importantes leyes. El Municipio libre constituye la base de la división territorial y de la organización política y administrativa del Estado.

La palabra "Municipio" viene del latín municipium, que significaba entre los antiguos romanos, ciudad principal que se gobernaba por sus propias leyes. De aquí nació también la palabra autonomía, cuya acepción original es la condición de una entidad o circunscripción territorial de regirse por normas propias.

Los municipios eran, en la antigua Roma, las ciudades que el Imperio incorporó a su territorio y a las que reconoció cierto grado de autonomía para manejar los asuntos de sus vecinos. Con antecedentes en las asambleas de vecinos de algunas ciudades del Imperio Romano, las municipalidades se organizaron en Europa a partir del siglo XII con la finalidad de atender los asuntos de la comunidad que, transcendiendo la competencia de la familia, no llegaba a serlo de la sociedad política. Las municipalidades son más antiguas que el Estado, puesto que éste surgió del proceso de unificación de las monarquías europeas en el Renacimiento; mientras que aquellas se formaron alrededor del siglo XII y aún antes, en el Imperio Romano, como las más espontáneas, humanas y amables de las sociedades, para atender los problemas diarios de los vecinos.

Las Municipalidades fueron realidades vitales antes que la ley se ocupara de ellas. La ley no las creó sino que simplemente reconoció su existencia. 